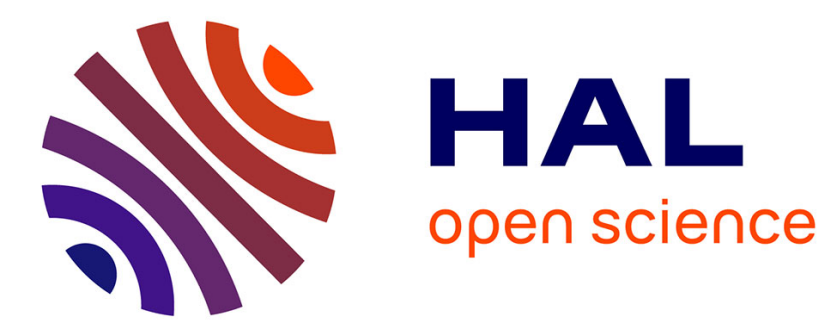

\title{
Excited-state excitons in strained quantum wells under pressure
}

\author{
D. Leong, A. Prins, A. Meney, D. Dunstan, K. Homewood
}

\section{To cite this version:}

D. Leong, A. Prins, A. Meney, D. Dunstan, K. Homewood. Excited-state excitons in strained quantum wells under pressure. Journal de Physique IV Proceedings, 1993, 03 (C5), pp.C5-331-C5-334. 10.1051/jp4:1993568 . jpa-00251655

\section{HAL Id: jpa-00251655 https://hal.science/jpa-00251655}

Submitted on 1 Jan 1993

HAL is a multi-disciplinary open access archive for the deposit and dissemination of scientific research documents, whether they are published or not. The documents may come from teaching and research institutions in France or abroad, or from public or private research centers.
L'archive ouverte pluridisciplinaire HAL, est destinée au dépôt et à la diffusion de documents scientifiques de niveau recherche, publiés ou non, émanant des établissements d'enseignement et de recherche français ou étrangers, des laboratoires publics ou privés. 


\title{
Excited-state excitons in strained quantum wells under pressure
}

\author{
D. LEONG, A.D. PRINS, A.T. MENEY, D.J. DUNSTAN and K.P. HOMEWOOD \\ Strained-Layer Structures Research Group, University of Surrey, Guildford, Surrey GU2 5XH, England
}

\begin{abstract}
We report measurements of the transition energies of the ground and excited state excitons in $100 \AA$ quantum wells of $\mathrm{In}_{0.15} \mathrm{Ga}_{0.85} \mathrm{As}$ and $\mathrm{In}_{0.18} \mathrm{Ga}_{0.82}$ As as a function of hydrostatic pressure by photoconductivity excitation spectroscopy and absorption spectroscopy in a diamond anvil cell. The pressure coefficients of the E1HH1 and E2HH2 transitions agrees well with eightband k.p theory provided the pressure coefficient of bulk strained InGaAs is given the anomalously low value reported previously [Wilkinson et al., Phys. Rev. B46, 3113 (1989)]. This result shows that the anomaly is an intrinsic property of the bulk strained crystal and is not associated with defects.
\end{abstract}

\section{INTRODUCTION}

Hydrostatic pressure is a powerful tool for the investigation of the band-structure of semiconductor heterostructures. In the tetrahedral semiconductors, pressure raises the $\Gamma$ minimum of the conduction band at about $10 \mathrm{meV}$ per kbar relative to the valence-band maximum; it raises the $L$ minimum at about half that rate; and it has little effect on the $\mathrm{X}$ minimum. Thus the application of pressures of the order of tens of kilobar is capable of turning a direct-gap semiconductor indirect by raising the $\Gamma$ minimum above crossover with the $\mathrm{L}$ or $\mathrm{X}$ minima.

Most work on semiconductor band-structure under pressure has been carried out using photoluminescence (PL) in a diamond-anvil high-pressure cell (DAC). This is because the experimental techniques are well-established and reliable, if not accurately described as easy; the DAC gives ready access to the pressure range required for any semiconductor experiment. ${ }^{1}$ Such experiments give access to the lowest band-edge states only, or to defect-related states. It is often desirable to carry out spectroscopy on higher states, and for this, an absorption spectroscopy or allied technique is required instead of emission spectroscopy. Rockwell $e t$ al. ${ }^{2}$ have reported measurements of photoreflectance in a DAC and this enabled them to observe the heavy-hole and light-hole exciton transitions in ZnSe. In this paper we report measurements using both absorption and photoconductivity excitation spectroscopy in a $\mathrm{DAC}$, in which we have studied the higher sub-bands of strained-layer InGaAs/GaAs quantum wells.

The pressure coefficient of the direct gap of strained InGaAs quantum wells has previously been found to be anomalously low, by Wilkinson $e t$ al. ${ }^{3}$ As remarked above, most tetrahedral semiconductors have values close to $10 \mathrm{meV} / \mathrm{kbar}$; for GaAs the value is $10.7 \mathrm{meV} / \mathrm{kbar},{ }^{4}$ for InAs Tsay et al. give about $10.2 \mathrm{meV} / \mathrm{kbar}^{5}$ and for InGaAs lattice-matched to $\mathrm{InP}$ we find $10.9 \mathrm{meV} / \mathrm{kbar}^{6}{ }^{6}$ Nevertheless, for 
In $\mathrm{Ga}_{1-x}$ As grown pseudomorphically on GaAs (strain $\varepsilon=0.07 x$ ) it is found to be $10.7-6 x$ meV/kbar. ${ }^{6}$ It is not clear whether this is due to anomalous elasticity in strained layers under pressure, or whether standard band-structure calculations are inadequate for structures under combined axial and hydrostatic strain. Alternatively, PL measurements may pick out untypical (defective) regions of the structure. Absorption measurements provide a spatial average over the density of states and are very insensitive to defects; they thereby avoid the last problem, and the added information on the higher sub-bands may also help to resolve the other questions.

\section{EXPERIMENTAL}

The samples were grown by molecular beam epitaxy under conditions described elsewhere. ${ }^{3}$ The sample studied by photoconductivity was a single $100 \AA$ quantum well of InGaAs in GaAs barriers, while to give a stronger absorption signal a second sample was grown with twenty $100 \AA$ wells separated by $500 \AA$ GaAs barriers. They were characterised by photoluminescence spectroscopy which indicated good quality growth but slightly different InGaAs compositions in the two samples.

Both absorption and photoconductivity excitation (PCE) experiments were done using laminated gaskets, described in detail by Leong et al., 7 in a miniature cryogenic diamond-anvil cell. 8 For absorption, the lamination enabled the sample space to be masked, so that with white light from a tungsten lamp incident on the sample, only light which passed through the sample was collected by the detection optics. The transmission spectra show the exciton peaks for the ground state and some higher states (Fig.1) and since it is only the energy of the peaks which interests us the spectra were not converted from transmission to absorption.

For the PCE experiments, the laminated gasket allowed wires to be passed between the laminations into the sample space. The wires were insulated from the steel gasket by a layer of alumina powder pressed into the surface of the steel and covered with spun-on epoxy resin. Two contact pads were evaporated onto the sample with a $50 \mu \mathrm{m}$ gap between them and the wires were bonded to the pads with a pressure bonder. White light was passed through a spectrometer and focused onto the sample; the photoconductivity was measured by applying a bias voltage and taking the signal from a load resistor in series with the sample. A typical spectrum is shown in Fig. 1.

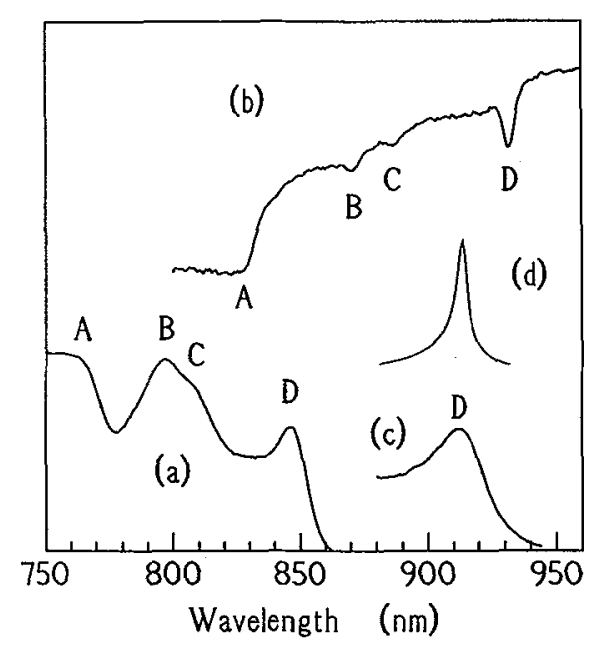

Fig.1: Typical spectra at $80 \mathrm{~K}$ are shown, (a) for the SQW sample using photoconductivity excitation spectroscopy at 10kbar, and (b) for the 20QW sample using absorption spectroscopy at $2 \mathrm{kbar}$. The features discussed in the text are marked-A: GaAs band edge, B: E2HH2, C: E1LH1 and D: E1HH1. The E1HH1 transitions observed in the SQW sample at ambient pressure by PCE (c) and by photoluminescence (d) are also shown to illustrate the small Stokes shift in this sample.

\section{RESULTS AND DISCUSSION}

\subsection{Results at 0kbar}

The spectra in Figure 1 show the GaAs band edge (A) and three distinct features (B, C and D) at lower energy. The lowest feature, $D$, in each sample is within a few $\mathrm{meV}$ of the photoluminescence peak 
and is therefore the E1HH1 exciton transition. The small Stokes shift is another indication of good growth. The energy of this peak was used to determine the indium content of the alloy wells by comparison with theory. The higher energy peaks B and C were then identified by comparison with theory (see Sec. 3.3).

\subsection{Results under Pressure}

All the exciton peaks moved to higher energy with pressure at rates close to $10 \mathrm{meV}$ per kbar, as expected for $\Gamma$-related transitions. Errors in pressure calibration of the order of \pm 1 kbar mean that small differences in pressure coefficients cannot be reliably measured from plots of peak energy against pressure. Instead, pressure is used as a dummy variable, and in Figure 2 the displacements of the various peaks from the GaAs band edge is plotted as a function of the GaAs band-edge energy. The error in peak position determination is about $5 \mathrm{meV}$ so that the light-hole data cannot be interpreted reliably and is not considered further.
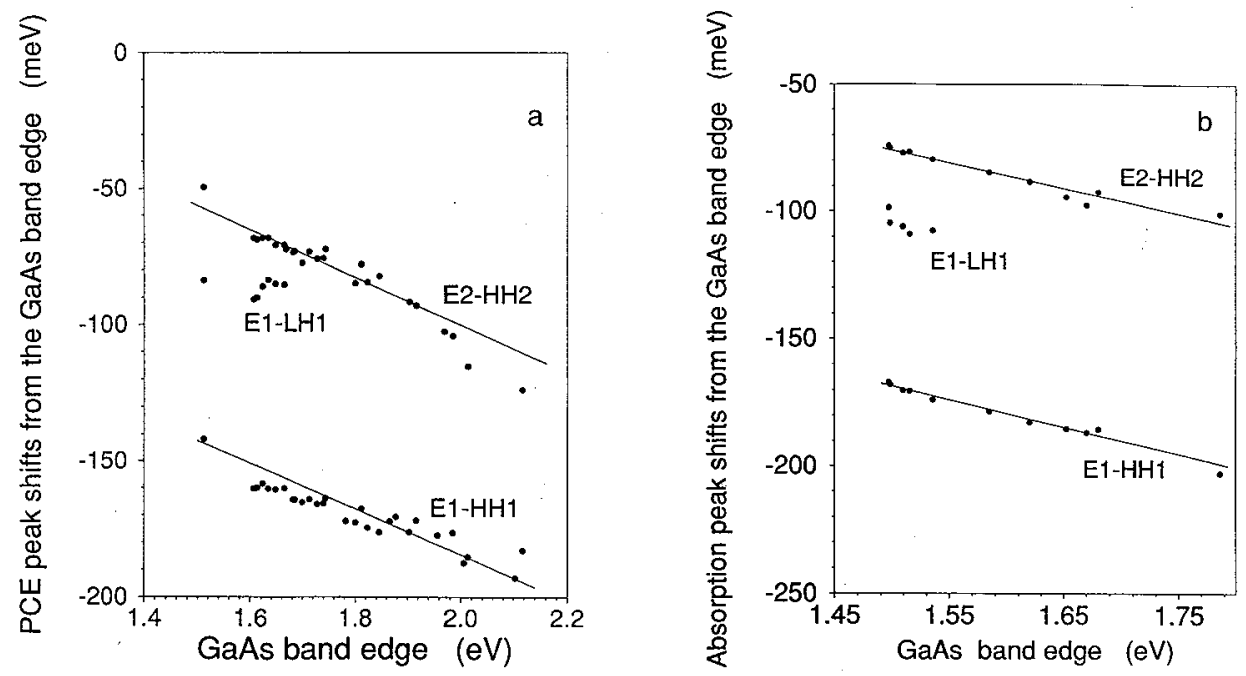

Fig. 2: The energy differences between the peak positions of the three low-energy features and the GaAs band-edge are plotted against the energy of the GaAs band-edge. In these plots, a pressure coefficient equal to that of GaAs corresponds to a horizontal line, and lower coefficients corresponds to lines sloping downwards. Data in (a) is from the SQW measured by PCE and the data in (b) is from the $20 \mathrm{QW}$ measured by absorption. The theoretical predictions are shown as solid lines.

\subsection{Theory}

The energies of the ground and excited states were calculated at ambient pressure and at high pressure using an eight-band $k_{p}$ model with parameter values from Amaud $e t$ al.. They are shown in Figure 3 as a function of indium content in the InGaAs wells. The lowest transition was fitted to these curves to determine the compositions, $x=0.15$ for the absorption $20 \mathrm{QW}$ sample and $x=0.18$ for the photoconductivity SQW sample. The least accurately known parameters are the valence band deformation potential $b$ and the band-offset ratio; these values were varied slightly to improve the fit to the higher transitions and the best fit was obtained with $b=1.7 \mathrm{eV}$ and the valence-band offset ratio $Q_{\nu}=0.35$. The light hole transition is shown over the range that the model predicts it to be Type I; at lower indium contents it is predicted to be Type II. We note that nothing in the theory indicates that the light-hole transition should disappear at a few kilobar, and we have no explanation for this observation. 
The pressure coefficients of the heavy-hole transitions are the most important prediction of the theory. They are very similar for both the E1HH1 and the E2HH2 transitions, and in both cases much less than the GaAs value- $9.6 \mathrm{meV} / \mathrm{kbar}$ for the $\mathrm{In}_{0.18} \mathrm{Ga}_{0.82} \mathrm{As}$ and $9.8 \mathrm{meV} / \mathrm{kbar}$ for the $\mathrm{In}_{0.15} \mathrm{Ga}_{0.85} \mathrm{As}$. The $\mathrm{E} 1 \mathrm{HH} 1$ transition comes from states with little confinement energy, and most of the electron and hole wavefunctions are in the quantum well; it is therefore expected to have a similar pressure coefficient to the bulk well material. In the case of the E2HH2 transition, much more of the electron wavefunction is in the $\mathrm{GaAs}$ barriers and the pressure coefficient is increased by this effect. However, the increase is completely offset by the increase in the effective masses with pressure, which leads to a reduced confinement energy and therefore reduces the observed pressure coefficient of the confined state.

\section{CONCLUSIONS}

The pressure coefficents observed for the $\mathrm{E} 1 \mathrm{HH} 1$ and $\mathrm{E} 2 \mathrm{HH} 2$ exciton transitions are in excellent agreement with the predictions of a model in which the bulk band-gap of the strained material is actually anomalously low. This shows that the anomaly is a property of the density of states of the perfect strained crystal and is not related to defects or otherwise unrepresentative small parts of the strained layer. The theoretical fit to the peak energies provides confirmation of the parameter values used in the calculation, particularly of the expression $10.7-6 x \mathrm{meV} / \mathrm{kbar}$ for the pressure coefficient of strained $\operatorname{In}_{x} \mathrm{Ga}_{1-x}$ As.

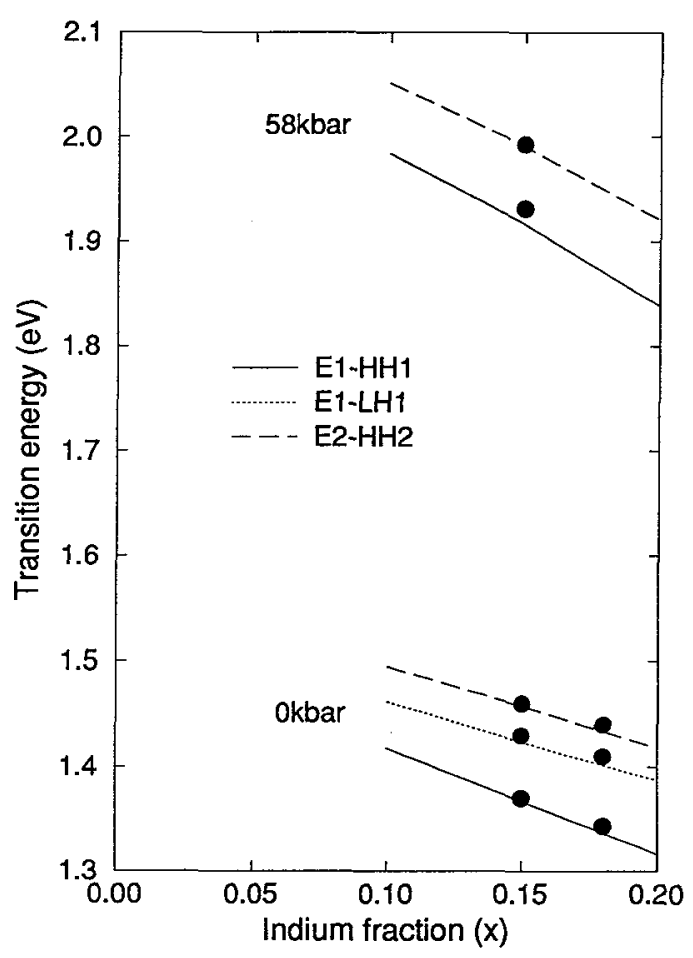

Fig.3: The theoretical predictions for the energies of the E1HH1, E1LH1 and E2HH2 transitions in a $100 \AA \operatorname{In}_{x} \mathrm{Ga}_{1-x}$ As quantum well are plotted as a function of $x$ at ambient pressure and at 58kbar. The data points show the exprerimental transition energies, fitted to the E1HH1 energy at Okbar to determine composition. The data points on the $58 \mathrm{kbar}$ curves are from the photoconductivity excitation spectrum recorded at this pressure.

\section{REFERENCES}

[1] I.L. Spain and D.J. Dunstan, J. Phys. E22 (1989) 923-933.

[2] B. Rockwell, H.R. Chandrasekhar, M. Chandrasekhar, A.K. Ramdas, M. Kobayashi and R.L. Gunshor, Phys. Rev. B44 (1991) 11307-11314.

[3] V.A. Wilkinson, A.D. Prins, J.D. Lambkin, E.P. O'Reilly, D.J. Dunstan and L.K. Howard, Phys. Rev. B42 (1990) 3113-3119.

[4] D.J. Wolford and J.A. Bradley, Solid State Commun. 53 (1985) 1069-1076.

[5] Y.F. Tsay, S.S. Mitra and B. Bendow, Phys. Rev. B10 (1974) 1476-1481.

[6] J.D. Lambkin and D.J. Dunstan, Solid State Commun. 67 (1988) 827-830.

[7] D. Leong, H. Feyrit, A.D. Prins, V.A. Wilkinson, K.P. Homewood and D.J. Dunstan, Rev. Sci. Instrum 63 (1992) 5760-5763.

[8] D.J. Dunstan and W. Scherrer, Rev. Sci. Instrum. 59 (1988) 627-630.

[9] G. Arnaud, J. Allègre, P. Lefebvre, H. Mathieu, L.K. Howard and D.J. Dunstan, Phys. Rev. B46 (1992) 15290-15301. 